\title{
قراءة في نقد نصوص العهد القديم عند الإمام
}

\section{ابن حزم}

\section{* الحسن العباقي}

مقدمة:

لقد كان للنصوص المقدسة أكبر الأثر في توجيه الجماعات البشرية بغض النظر عن مصدر هذه النصوص سواء أكان الهياً أم بشرياً.

والمتأمل في تاريخ الشعب اليهودي في نشاطاته التي جاءت بعد السبي البابلي 1 خاصة؛ يجد أن أغلبها إن - لم تكن كلها - كانت مؤطرة بالنص المقدس، سواء نص العهد القديم أو نص التلمود في مرحاة لاحقة، وبتعبير أكثر دقة يمكن القول إنه كان شديد الحرص على تأصيل سلوكياته تجاه الآخرين؛ تلك السلوكيات التي كان العداء والاحتقار للآخر سمتها الأساسية، وما ذلك إلا ليضفي عليها نوعا من المشروعية. غير أن الحديث عن هذا المستوى من المشروعية يدفعنا لمساءلة النصوص المعتمدة في عملية التأصيل هذه، لنقف على مدى قداستها. تلك القداسة التي تحدد وفقا لقداسة المصدر من جهة، وصحة المضمون من جهة ثانية، الشيء الذي لا يمكن الإجابة عنه إلا إذا أخضعناها - كما كان حال المحدثين مع النصوص الحديثية - المى دراسة نقدية على مستوى السند والمتن.

ومع انه قد اضطلع بهذه المهمة العديد نم العلماء ومن ملل شتى، تبقى دراسة الإمام الجليل أبو محمد علي بن الحزم الظاهري أمتنها على الاطلاق وذلك ف كتابيه "الفصل في الملل والأهواء والنحل" و"الرد على ابن النغريلة اليهودي"، والكتاب الأول قد جعل من الإمام ابن حزم المؤسس الحقيقي لعلم مقارنة الأديان كما شهد له بذلك 
أعداءه2 قبل محبيه، حيث عرض فيه جملة من العقائد عرضا نقديا وناقشها نقاشا متينا -وإن كان مصحوبا بالكثير من السب والشتم- ومن ذلك مناقشته لنصوص العهد القديم التي اتسمت الى جانب عنفها بإحاطة كبيرة بالموضوع سندا ومتنا.

وإن المطّلع عى ما كتب بعد ابن حزم ليقرر وبكل طمأنينة أن الذين جاءوا بعده كانوا عالة عليه، أو أقل تقدير ساوروا على نفس الدرب الذي سار عليه، فاقتفوا خطواته واتبعوا منهجه في التعامل مع النص. ولم يكن هذا مقتصرا

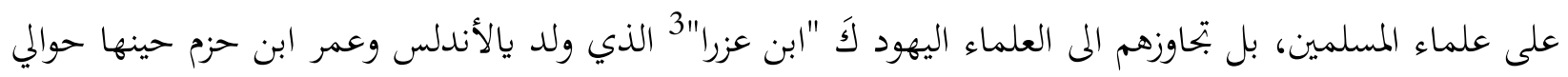
اربعين سنة والذي قال عنه "سيبونزا"4 انه اول من تنبه الى الأخطاؤ الواردة في نصوص العهد القدم، إلا أن قضية

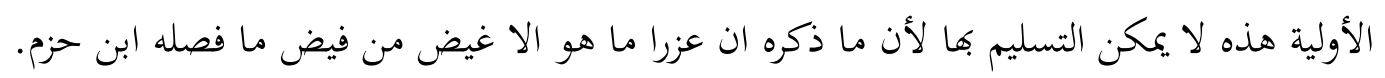

وان عالما كابن عزرا يتقن اللغة العربية، من المستبعد جدا ان يهمل كتابي ابن حزم السالفي الذكر وهما يوجهان أعنف نقد لأقدس نص عنده. وحتى ان لم يشر اليهما في كتاباته فلا شك اهما تركا اثرا عميقا في نفسه، دفعه الى كتابة تلك الاشارات التي اعتمدها سبينزوا في نقده لنصوص العهد القديم في كتابه "رسالة في اللاهوت والسياسة" الذي قض به مضاجع اليهود في عصره.

وهدفنا من هذه القراءة في نقد نصوص العهد القديم عند ابن حزم ان نبين للقارىء الكريع أيّا كان معتقده، ان تلك النصوص التي يؤصل بها اليهود معتقداتم واختيارهم -كما هو الشأن في اسطورة شعب الله المختار واسطورة ارض الميعاد - لا ترقي الى المستوى الذي تضفي فيه المشروعية عليها لأها بجتثة الأصل سندا ومتنا، بالأدلة العلمية

امثال المستشرق الاسباني أسين يلاثيوس الذي ترجم كتاب الفصل من الملل والاهواء والنحل الى اللغة الاسبانية وقدم للترجمة بمقدمة طويلة تتجوز

المائة صفحة اشاديفها بالإمام ابن حوم واعتبره المؤسس الحقيقي لعلم مقارنة الاديان.

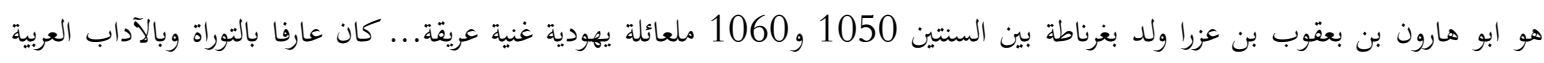

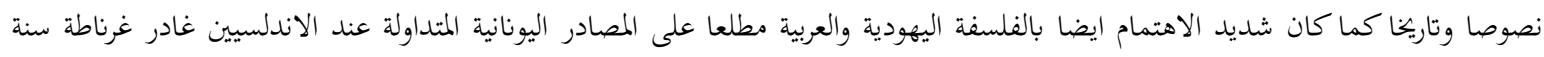

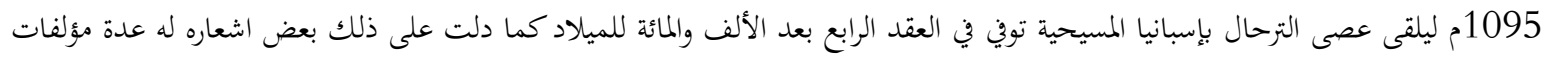

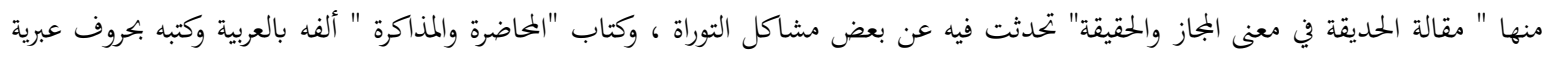

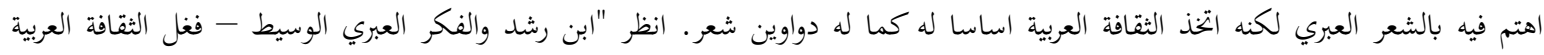

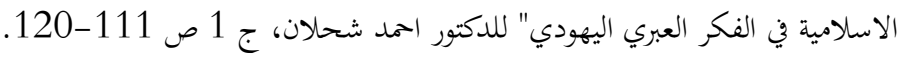

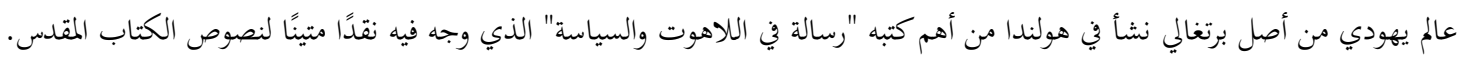


لقد تطرق ابن حزم لليهودية في القسم السادس 5 من كتاب "الفصل" الذي خصصه لأصحاب الملل المنكرة لبعض النبوات وتؤمن ببعضها الآخر، وكانت بداية كلامه عن فرقها التي حددها في خمسة وهي: السامرية6

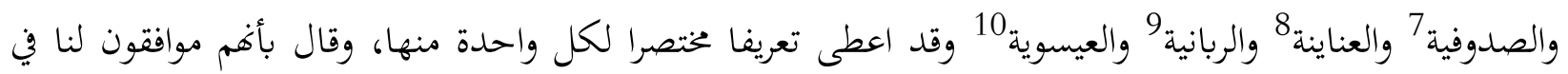
الإقرار بالتوحيد ثم بالنبوة وبآيات الأنبياء عليهم السلام بنزول الكتب من عند الله إلا أفم فارقوانا في بعض الأنبياء.

وقج تطرق لنقد العهد القديم على المستويين، الأول يتعلق بمحتوى نصوصه، عالجه في ثمانة وخمسين فصلاً وكان هدفه منه بيان ما تحتوي عليه هذه النصوص من كذب وتحريف واضطراب وتناقضات. 12 والثاني يتعلق بدراسة الأحداث التاريخية، وقد اكتفى فيه بفصلين اثنين حاول فيهما بيان استحالة سلامة التوراة في التحريف من ظل ظروف كالتي عاشها بنو اسرائيل ابان القرون التي تلت موسى عليه السلام.

وسوف نلاحظ في تعاملنا مع الموضوع على نفس الخطة التي اتبعها ابن حزم مع الحرص على الاختصار ما امكن فيما يتعلق بفصول المستوى الأول وبالشكل الذي لا نخل فيه بالمقصود.

قسم الإمام ابن حزم الفرق المخالفة الى ستة اقسام ابتدأ بأبعادها عنه وسمى اصحابها منكري الحقائق واختم بأقربها وهي اصحاب الديانات التوحيدية. يقولون ان القدس هي نابلس ولا يعرفون حرمة لبيت المقدس ولهم توراة فيلا التوراة التي بأيدي سائر اليهود ويبطلون كل نبوة في بني اسرائيل بعد

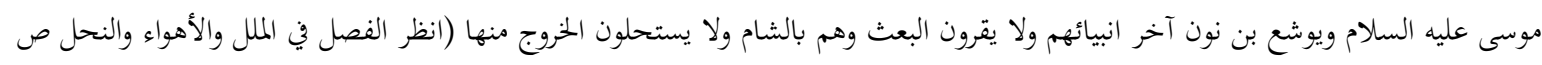

.(178-177

$$
\text { نسبة الى رجل اسمه صدوق وهم الذين يقولون بأن عزيز ابن الله دون سائر فرق اليهود كانوا بجهة اليمن (نفسه ص 178). }
$$

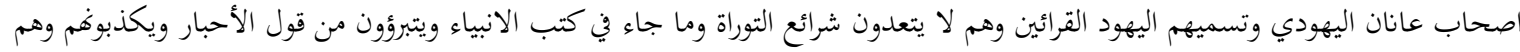

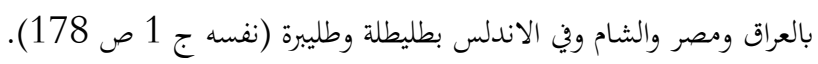

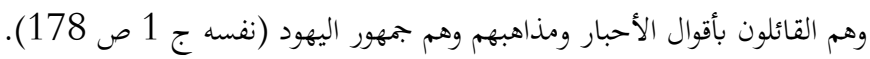

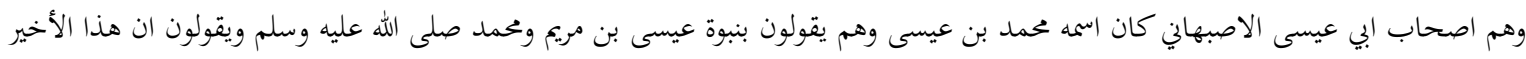

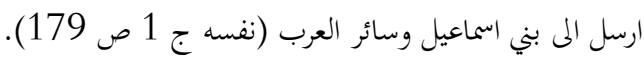

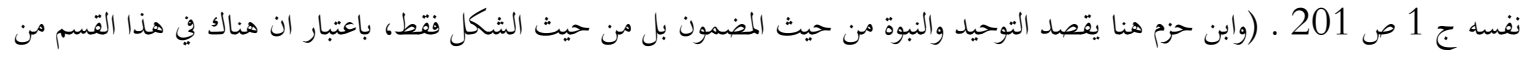

لا يقول بوجود اله واحد كالجوس او اصحاب الثليث من النصارى وكذلك لأن هناك من لا يؤمن بعدد من الأنبياء أما مضمون التوحيد والنبوة

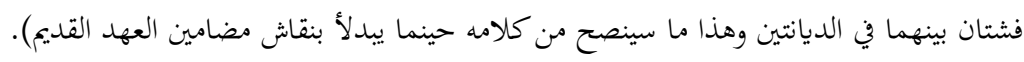

$$
\text { الفصل ج1 ص: } 288 .
$$




\section{أولا قراءة ابن حزم النقدية لمحتوى اسفار العهد القديم}

بعد ذكر الهدف من هذه الدراسة الذي هو بيان ما في اسفار العهد القديم من كذب على الله والملائكة والانبياء عليهم السلام 13 يلزم ابن حزم نفسه بألا يخرج من الكتب المذكورة (ويقصد بها اسفار التوراة) شيئاً يمكن ان

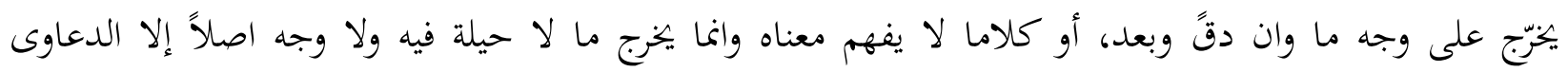
الكاذبة التي لا دليل عليها اصلاً لا محتملاً ولا خفياً. 14 وقد خصص الفصل الأول للحديث عن "التوراة السامرية" وترك السبعة والخمسين فصلاً الأخرى للتوراة المقابلة التي تؤمن بها باقي الفرق اليهودية، ولعل سبب هذا التفاوت هو كون التوراة السامرية معتمدة من فرقة واحدة ليست ذات وزن مقارنة مع غيرهالا من فرق اليهود- خاصة الرانيين-. والشيء الذي اثاره هنا هو تبادل التهم بين السامرية من جهة وباقي فرق اليهود من جهة ثانية، وطعن كل منهم في التوراة التي بيد الآخر بالتحريف، ليثبت أن لا مفر من أن تكون التوراة محرفة لاعتبار أول هو تعدد النسخ واختلافها، 15 ويمكن تقسيم الموضوعات التي عالجها في هذه الفصول الى ثلاثة وهي: "الألوهية والملائكة والنبوة"، لكنها لم تكن متساوية من حيث حظها من التناول، لأن الذي كان يشغل ان حزم هو اخراج ما بدا له كذباً وتحريفاً من التوراة، فكان حظ كل قسم بحسب حظه من التحريف في التوراة نفسها.

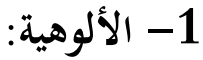

وقد تطرق لموضوع الالوهية من جانبين، الأول فيه ما ينسب لله عز وجل قي التوراة من بتحسيم وتشبيه ونقص، والثاني خصصه لما احتوته من اخطاء جغرافية وتاريخية وحسابية يستحيل معها ان تكون ذات مصدر إلهي، لأن الله قد احاط بكل شيء علماً فلا يقبل البتة تصور الخطأ فيما يلي من عنده. أ-ما ورد في التوراة من صفات النقص في حق الله عز وجل:

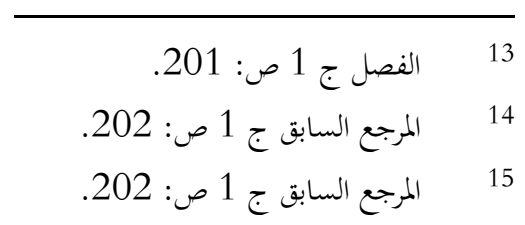


المثال الأول: تعرض ابن حزم لما جاء في سفر التكوين من ان الله خلق آدم كصورته وشبهه 16 فكان رده كالآتي:"لو لم بقل إلا كصورتنا لكان له وجه حسن ومعنى صحيح، وهو ان نضيف الصورة إلى الله تعالى اضافة الملك والخلق كما تقول هذا عمل الله وتقول للقرد... هذه صورة الله أي تصوير الله... لكن قوله كشبهنا منع التأويل وسدّ المخارج وقطع السبل وأوجب شبه آدم لله عز وجل.... وحاشى الله أن يكون له مثل أو شبه". 17 المثال الثاني: تعرضه لما جاء في سفر التكوين أيضاً "وقال الله هذا آدم قد صار كواحد منا في معرفة الخير والشر والآن كي لا يمد يده من شجرة الحاة ويأكل ويحيا الى الدهر فطرده الله من جنات عدن". 18

فهذا الكلام في نظر ابن حزم يطعن في التوحيد ويوحي بتعدد الآلهة بل "قد أدى... بكثير من خواص اليهود الى الاعتقاد أن الذي خلق آدم لم يكن إلا خلقاً خلقه الله تعالى قبل آدم وأكل من الشجرة التي أكل منها آدم فعرف الخير والشر ثم أكل من شجرة الحياة فصار الها من جملة الآلهة". 19

وهناك فصول أخرى20 عالج فيها ابن حزم موضوع الألوهية محاولا كشف الحجاب عما احتوته التوراة من تصورات منحرفة عن الذات الإلهية، مما يجعل الإنسان موقناً تماماً بتحريفها.

\section{ب- ما ورد في التوراة من أخطاء يستحيل معها نسبتها الى الله عز وجل:}

المثال الأول: وهو مرتبط بعلم الجغرافية، تعرض فيه ابن حزم للنص الآتي من سفر التكوين:

"وغر يخرج من عدن فسيقي الجنات ثم يفترق فيصير اربعة اسم أحدها النيل وهو محيط بجميع بلاد زويلة... واسم الثاني جيحان وهو محيط بجميع بلاد الحبشة واسم ثالث الدجلة وهو السائر شرق الموصل واسم رابع الفرات وأخذ الله آدم ووضعه في جنات عدن". 21

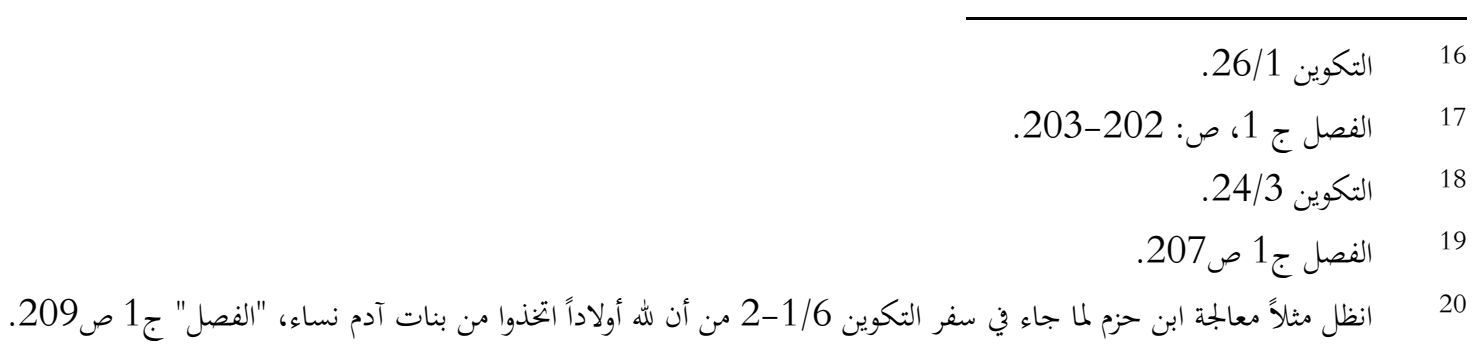


قال ابن حزم: "في هذا الكلام من الكذب وجوه فاحشة قاطعة بأها من توليد كذاب مستهزء"،22 وهو هنا ينفي تماماً الإلهية عن هذا الكلام ويؤكد بقوله انه لا يمكن ان يصدر الاعم كذاب مستهزء ثم يتمتم قائلا: "أول ذلك اخباره ان هذه الاربعة تفترق من النهر الذي يخرج من جنات عدن التي اسكن الله فيها آدم... وكل من له ادنى معرفة بالميئة وبنصبه الربع المعمور من الأرض أو مشى الى مصر والشام والموصل يدري ان هذا كله كذب فاضح وان يخرج النيل من عين الجنوب ومصبه قبالة الاسكندرية فأما جيحان فيخرج من بلاد الروم حتى يصب فب البحر الشامي وأما دجلة فمخرجها من أعن بقرب خلاط من عما أرمينية واما الفرات فمخرجه من بلاد الروم على يوم من (قالي) ... فهذه كذبة شنيعة لا مخلص منها والله لا يكذب". 23

ومن خلال هذا البيان الدقيق المستوحى من علم ابن حزم الجيد بالجغرافية، يؤكد مرة أخرى شناعة ما احتوته التوراة من الكذب الذي يستحيل ان يصدر عن الله عزّ وجل، وقد استمر بعد هذا في اعطاء معلومات اخرى حول هذه الأنمار خلافا لما جاء في التوراة.

المثال الثاني: سنختار مثالاً يتبط بعلمي الحساب والتاريخ معاً، ونشير قبل ذلك الى ان ابن حزم قد ساق في هذا الباب أمثلة كثيرة أكّد من خلالها أن الذي ألف التوراة لم يكن له علم بالحساب، منها كلامه عن مدة تعذيب بني اسرائيل،24 ومدة بقائهم في مصر، 25 والفارق الزمني بين الأحداث في التوراة مقارنة مع الإنجيل مرتبطة بالطوفان وأبناء نوح عليه السلام26 وسوف اقتصر على ما ساقه عن عُمُر سام ابن نوح عند وقوع الطوفان حيث قال: "قال توراقم ان نوحا لما بلغ خمسمائة سنة ولد له يافت وسام وحام ثم ذكر ان نوحا إذْ بلغ ستمائة سنة كان الطوفان ولسام يومئذ مائة سنة وقال بعد ذلك إن سام لما كان ابن مائة سنة ولد أرفكشاد لسنتين بعد الطوفان"27 ففي الحساب الأول أن سام لما كان عمره مائة سنة وقع الطوفان، وفي الثاني لما كان عمره مائة سنة كان قد مر على

$$
\begin{aligned}
& 21 \\
& 22 \\
& 23 \\
& 24 \\
& 25 \\
& 26 \text { 2 } 210 \\
& 27 \text { المرجع السابق ج1 ص: } 212 .
\end{aligned}
$$


الطوفان سنتين، ونتيجة لهذا الاضطرب قال ابن حزم "وهذا كذب فاحش وتلون سمج وجهل مظلم... حاشى لله من مثله".

$$
\text { وهو هنا ينزه الذات الإلهية عن الكذب والخظأ وينسبهما لمن ألف التوراة. }
$$

\section{2- الملائكة:}

لم يخصص ابن حزم لموضوع الملائكة فصولا كثيرة، فهو اقل حظاً من الموضوعين الآخرين (الالوهية والنبوة)، ومع ذلك فقد اوضح الصورة التي توجد في التوراة عن الملائكة، الشيء الذي لا يمكن ان يكون كذبا وتريفا.

المثال الأول: جاء في التوراة "فلما بدأ الناس يكثرون على ظهر الأرض وولد لهم بنات فلما رأى أولاد الله بنات آدم أغن حسان اتخذوا منهن نساء وكان يدخل بنوا الله بنات آدم ويولد لهم حراما وهم الجبابرة". 29 وقد علق على هذا الكلام بقوله:"هذا ممق ناهيك به وكذب عظيم إذ لله أولادا ينكحون بنات آدم وهذه مصاهرة تعالى الله عنها - حتى إن بعض اسلافهم قال انما عني بها الملائكة، وهذه كذبة، الا اها دون الكذب في ظاهر اللفظ، 30 وسواء كان قصد المؤلف اولاد الله او الملائكة فالأمر سيان، ولا يخلو من كذب، اذ كيف يتصور ان يساور الملائكة شهوة كالبشر، وحتى ان حصل هذا فكيف يدخلون ببنات آدم بالحرام؟ ويولد لهم ابناء من حرام!!

هذا بالفعل ما لا يمكن قبوله عن الملائكة الذين يفعلون ما يؤمرون.

$$
\begin{aligned}
& 28 \text { 2 } 212 \text { المرجع السابق ج1 ص: } 2012 .
\end{aligned}
$$

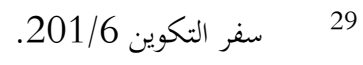

$$
\begin{aligned}
& 30
\end{aligned}
$$


المثال الثاني: تعرض ابن حزم لما جاء في سفر التكوين "وبتلى الله لإبراهيم عند بلوطات ممرا وهو جالس عند باب الخباء عند حمي النهار ورفع عينيه ونظر فإذا بثلاثة نفر وقوف أمامه فنظر وركض لاستقبالهم عند باب الخباء وسجد على الارض وقال يا سيدي ان كنت قد وجدت نعمة في عينك فلا تتجاوز عبدك، ليؤخذ قليل من ماء واغسلوا ارجلكم واستندوا تحت الشجرة وأقدم لكم كسرة من الحبز تشتد ها قلوبكم وبعد ذلك تمضون... م اخذ لبناً والعجل الذي طبخه ومدها امامهم وبقي واقفا في خدمتهم تحت الشجرة وهم يأكلون". 31 علق ابن حزم على هذا بكلام في غاية الرزانة والدقة، ونسف ما فيه من "ضلال" - كما أسماه- سواء في حق الله تعالى او في حق الملائكة، هذا نصه: "في هذا الفصل آيات من البلاء شنيعة نعوذ بالله من قليل الضلال وكثيره، فأول ذلك اخاره ان الله تعالى بتحلى لابراهيم وانه رأى الثلاثة هم الله، فهذا هو التتليث بعينه... بل هو اشد... لأنه اخبار بشخوص ثلاثة والنصارى يهربون من التشخيص... قإن كان أولئك الثلاثة ملائكة-وهكذا يقولون- فعليهم في ذلك ايضا فضائح عظيمة وكذب فاحش الوجوه:

أولها: من المحال والكذب ان يخير الله تعالى بتحلى له وانما تجلى له ثلاثة من الملائكة.

ثانيها: ان يخاطب اولئك الثلاثة بخطاب الواحد، وهذا ايضا محال.

ثالثها: سجود الى الملائكة، فإنه من الباطل ان يسجد رسول الله عله السلام وخليله لغير الله.

رابعها: خطابه لمم بأنه عبدهم.

31 
خامسها: قوله يؤخذ قلينٌ من الماء ويغسل ارجلكم وأقدم كسرة من الخبز تشتدّة بها قلوبكم... فهذا كذب لأن ابراهيم يعلم ان الملائكة لا تشتد قلوهما بكسر الحبز.

سادسها: اخباره اغم أكلوا الخبز والشوى والسمن واللبن.

وحاشى له ان يكون خبرا عن الله تعالى أو الملائكة" "32 وبعد هذا التعليق يحكي ابن حزم القصة كما جاءت في

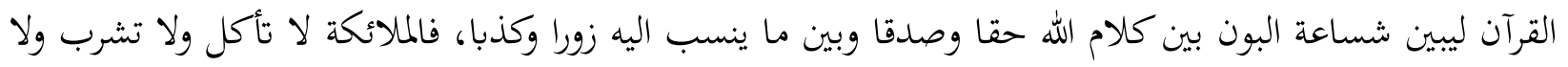
يصيبها الكلل من فعل أمرت به كي تقعد وتستريح أو تستظل.

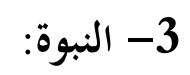

وهي التي نالت الحظ الأوفر من الفصول السبعة والخمسين المخصصة لنقد التوراة، ولا غرابة في ذلك، فالأنبياء

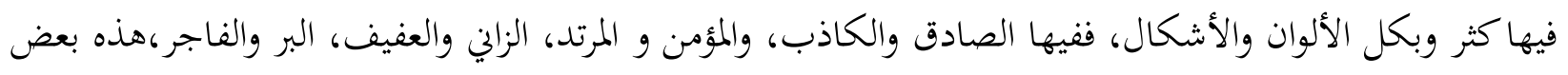

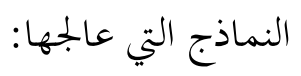

المثال الأول: جاء في التوراة "وأقام لوط في المغارة هو وابنتاه فقالت الكبرى للصغرى ابونا شيخ ليس في

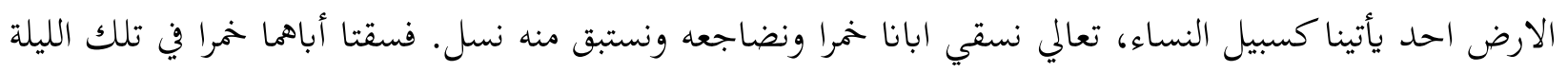

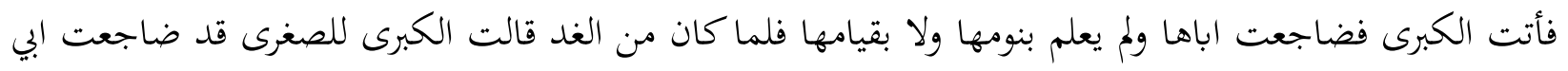
امس تعالي نسقيه الحمر هذه الليلة وضاجعيه هذه الليلة انت ونستبقي من ابينا نسلا فسقتاه تلك الليلة خمرا واتت الصغرى فضاجعته ولم يعلم بنومها ولا بقيامها، ومملت ابتتا لوط من ابيهما فولدت الكبرى (مؤاب) وهو ابو المئابين 
الى اليوم وولدت الصغرى (ابن عمي) وهو أبو العمونيين الى اليوم"33 ولا يخفى ما يوجد في هذا الكلام من قبائح وفضائح تقشعر من سماعها جلود المؤمنين العارفين حقوق الأنبياء عليهم السلام كما قال ابن حزم، 34 ليكم ما ذكر: أولا: ما ذكر عن بنتي لوط عليه السلام من قولما:"ليس احد في الأرض يأتينا كسبيل النساء تعالي نسقي ابانا خمرا ونضاجعه ونستبق منه نسلا"، فهذا كلام احمق في غاية الكذب... اترى كان انقطع نسل ولد آدم كله حتى لم

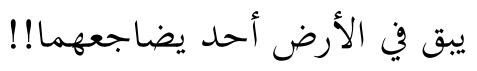

فكيف الموضع معروف المى اليوم، ليس بين تلك المغارة... وقرية سكنى ابراهم عليه السلام والا فرسخ واحد لا

ثانيا: اطلاق الكذاب... لعنه الله هذه الطومة على الله عز وجل من انه اطلق نبيه ورسوله على هذه الفاحشة

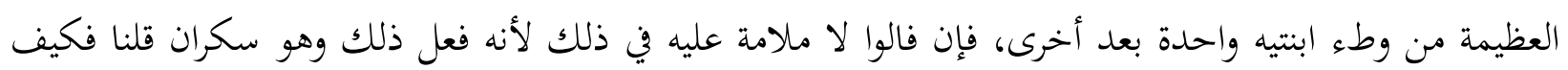
عمل اذا رآهما حاملتين واذ رآهما قد ولدتا... واذ رآهما تربيان أولاد الزنا هذه الفضائح لا بد وتوليد الزنادقة المبالغين في الاستخفاف بالله وبرسله".

فهذا المثال من أمثاله كثيرة تحكي اقبح الاقعال واذمها عن الانبياء والرسل، وقد تطرق اليها لبن حزم في كتابه هذا مبيّنا استحالة وصف الأنبياء والمرسلين الذين اصطفاهم الله من بين خلقه واكرمهم بالعصمة بهذه الصفات. المثال الثاني: عن نبي الله هارون أخو موسى عليهما السلام، فقد جاء في التوراة انه لما ذهب موسى لميقات ربه طلب بنو اسرائيل منه ان يصنع لهم إلها لأفم لا يعلمون ما جرى لموسى، فأمرهم بجمع أقراط الذهب من آذان نسائهم وبناقم وابنائهم، وصنع منع عجلا وقال هذا إلهكم الذي أخرجكم من مصر ثم بنى له مذبحا. 36

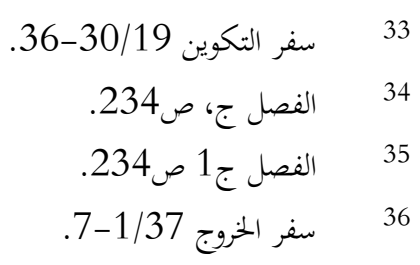


علق ابن حزم على هذا بقوله:"هذا الفصل عفا ما قبله وطمّ عليه أن يكون هارون وهو بني مرسل يتعمد ان يعمل إلها يعبدونه من دون الله عز وجل.. ويبني للعجل مذبحا... إن هذا لعجب! نبي مرسل كافر مشرك!!! يعمل لقومه إلها من دون الله".

وبعد هذا التعجب ينطلق ابن حزم بكلام لاذع في حق كاتب هذه الأكاذيب ومن يؤمن بها قائلاً: "أترى بعد استخفاف النذل الذي عمل لهم هذه الخرافة بالأنبياء عليهم السلام استخفافُ!! حاشى الله من هذا، أوتون بعد

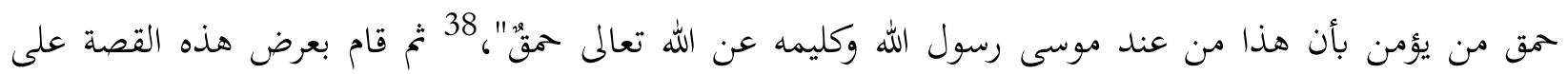
نظيراتما في القرآن ليبين الحق من الباطل وينزه النبوة مما لصق من دنايا بتعل من هذه الأمور أكبر دليل من تحريف الكتاب واستحالة نسبته المى موسى عليه السلام.

وخلاصة القول عنده ان المتأمل في محتوى التوراة لا يستطيع بحال من الأحوال ان يسلم بإلهية مصدرها، ولا يساوره شك في أها مكذوبة، كان الغرض منها تحريف تصورات بني اسرائيل حول الألوهية والملائكة والنبوة، وهذا بالفعل ما حصل. فلا مفهوم الألوهية بقي نقياً من الشوائب ولا مفهوم الملائكة حافظ على ماهيته، ولا مفهوم النبوة نجا من الأباطيل، فغرقت المفاهيم الثلاثة في أثون المادية المقيتة والشهوانية المظلمة والنزوات القاتلة، حتى لم يبق للإله عندهم حرمة ولا للملائكة مكانة ولا للأنبياء احترام.

المثال الثالث: وموضوعه ما جاء في سفر الثثنية من قول موسى لقومه: "إن طلع فيكم ببي وادعى أنه رأى رؤيا وأتاكم ما يكون وكان ما زصفه ثم قال لكم بعد ذلك اتبعوا أبناء آلهة الأجناس فلا تسمعوا له". 39

قال ابن حزم "فهذا الفصل... تدسيس كاف مبطل للنبوات كلها، لأنه أثبت النبوة بقوله إن طلع فيكم ببي... ثم أمرهم بمعصيته الى اتباع آلهة الأجناس، وهذا تناقض فاحش. ولئن جاز ان يكون نبي يصدق فيما ينذر به يدعو 
الى الباطل والكفر فلعل صاحب هذه الوصية من أهل هذه الصفة... وهل ها هنا شيء يوجب تصديقه واتباعه ويبينه من الكذابين إلا ما صحح نبوته من المعجزات". 40

ويؤكد ابن حزم انه من المستحيل في حق النبي الذي ثبتت نبوته بالمعجزات ان يأمر بالباطل، ومن المستحيل على من ليس بنبي ان تظهر على يده المعجزات، وبالتالي فلا بجال لذلك الكلام المنسوب الم موسى عليه السلام، لأن تصديقه ينفي نبوة موسى الذي لم تعرف نبوته الا بما اتى به من معجزات، وقد ختم الفصول السبعة والخمسين في نقد محتوى التوراة بتعليق دقيق على الفقرات الآتية من سفر الثنية، "فتوفي موسى عبد الله بذلك الموضع في ارض مواب مقابل بيت فغور ولم يعرف آدمي موضع قبره الى اليوم... ولم يخلف موسى في بني اسرائيل نبي مثله ولا يكلمه الله مواجهة". 41

وكان تعليقه كما يلي: "هذا آخر توراتم وتمامها وهذا الفصل شاهد عدل وبرهان تام ودليل قاطع وحجة صادقة في ان توراتم مبدلة وانما تاريخ مؤلف، كتبه لهم من تحرض بجهله أو تعمد بفكره، واها غير منزلة من عند الله تعالى؛ إذ لا يمكن ان يكون هذا الفصل منزلا على موسى في حياته وقوله لم يعرف قبره آدمي الى اليوم بيان لما ذكرنا كاف، وانه تاريخ الف بعد دهر طول ولا بد". 42

تم يستطرد قائلا بأن فصلا واحدا منى الفصول التي ذكر موجب لتحريف التوراة، فكيف وهي سبعة وخمسون فصلا قد بحمع الفصل منها سبع كذبات او مناقصات. 43

ثانيا: حال التوراة عبر التاريخ بني اسرائيل

\begin{tabular}{|c|c|}
\hline \multicolumn{2}{|l|}{ الفصل ج1 ص: 282-283. } \\
\hline التثنية 5/34-12. & \\
\hline .285 & \\
\hline ح1 ص: 285 & \\
\hline
\end{tabular}


ان كان ابن حزم قد تحدث عن تاريخ بني اسرائيل، فلم يكن يهمه منه الا مصير التوراة، حيث يقول "ونصف ان شاء الله تعالى حال كون التوراة عند بني اسرائيل من أول دولتهم إثر موت موسى عليه السلام الى انقراض دولتهم الى رجوعهم الى بيت المقدس الى ان كتبها عزرا الوراق بإجماع من كتبهم واتفاق من علمائهم دون خلاف يوجد... وما اختلفوا فيه... نبهنا عليه ليتيقن كل ذي فهم اها محرفة مبدلة". 44

وابن حزم هنا يريد كون التوراة لم تكن لتسلم من التحريف في تاريخ كتاريخ بني اسرائيل، لأفا من جهة لم تكن عند عموم الناس بل كانت عند "الكوهن الأكبر" وكل كتاب يبقى عند فئة بعينها فسلامته من التحريف والتبديل تكون ضعيفة، ومن جهة ثانية لأن تاريخ بني اسرائيل مليء بالحروب والدمار والسبي والحرق الى درجة يستحيل معها بقاء التوراة سالمة، خاصة وأن المعابد هي أول ما كان يتعرض للتخريب والنهب عندهم. ومن جهة ثالثة -هي الأهملأن ملوك بني اسرائيل بعد انقسام المملكة كان جلّهم على الكفر، محارب للإيمان ومخرب للمعابد، فلم تكن التوراة لتنجو منهم، وسوف نعرض هذا في جداول زيادة في الوضوح.

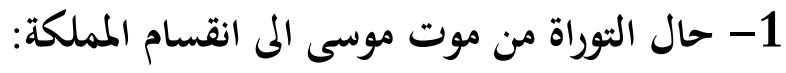

\begin{tabular}{|c|c|c|}
\hline طبيعة حكمه & مدة ولايه & 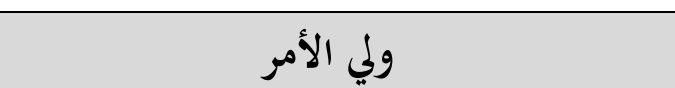 \\
\hline دبر أمرهم في استقامة وألزمهم الدين & (31 & يوشع بن نون \\
\hline 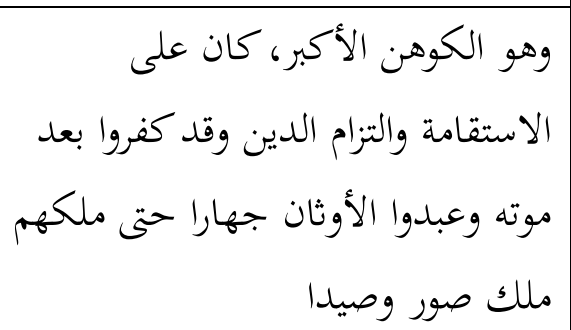 & 25 سنة & فيخاس بن عازار بن هارون الذي كانت معه \\
\hline على الكفر & 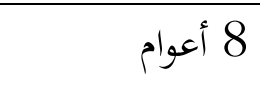 & ملك صور وصيدا \\
\hline على الإيمان وبموته كفروا جميعا وعبدوا & 40 سنة & عال بن كنار بن أخي كالب بن يقنه بن يهوذا \\
\hline على الكفر & 18 سنة & عقلون ملك ني مؤاب \\
\hline
\end{tabular}

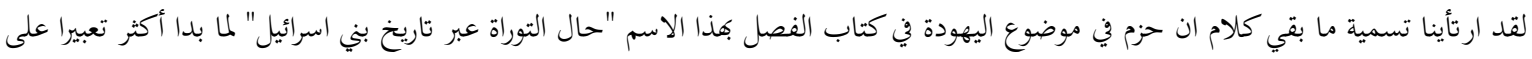
ما كتبه ابن حزم من العنوان الذي وضعه المققان.

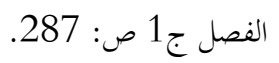




\begin{tabular}{|c|c|c|}
\hline على الإيمان & قيل 80 سنة وقيل & بنيامين بوذ قرافيل من سبط افرايم وقيل من سبط \\
\hline 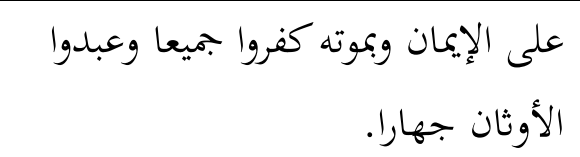 & 25 سنة & سمعان بن غاث بن سبط الآثار \\
\hline على الكفر . & 20 & مراش الكنعني \\
\hline 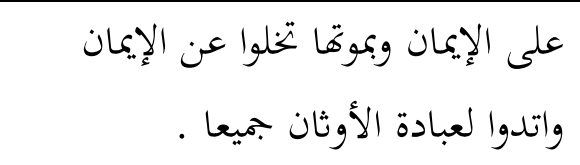 & 40 & دبورا (امرأة) من سبط يهوذا \\
\hline على الكفر & 7 7 & عويزب وزاب ملك بني مدين \\
\hline 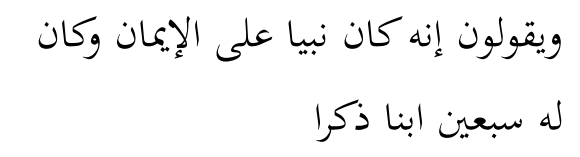 & 40 سنة & جدئون بن بواس من سبط افرايم وقيل سبط \\
\hline 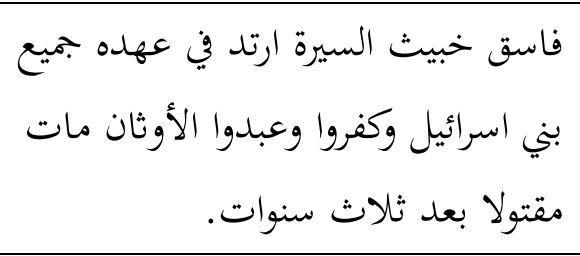 & 3 & أبو ملك بن جدعون \\
\hline لم يوجد بيان أكان على الكفر أو & 25 سنة & مولع بن رقوا من سبط يساخر \\
\hline كلى اسرائيل بعد ملإيمانى وكان موته مدينة وقد 32 ولدا ذكرا ولّى & 6 6 سنة & بابين بن جلعاد من سبط منسي \\
\hline على الكفر . & 13 سنة & بنوا عمون \\
\hline كان فان فاسقا ابن زانية نذر إن ظفر بعدو الله أول من يلقاه من منزله & 6 & هيلغ بن جلعاد من سبط منسي \\
\hline على الاستقامة & 6 أو 7 سنين & أفصات من سبط يهودا \\
\hline لا يوجد بيان لطبيعة حكمه & 10 & أيكون من سبط زيلون \\
\hline 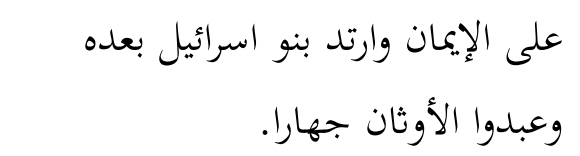 & 8 سنين & عبدون بن هلال من سبط افرايم \\
\hline
\end{tabular}




\begin{tabular}{|c|c|c|}
\hline على الكفر. & | 40 سنين & الفلسطنيون والكنعانيون وغيرهم \\
\hline كان مشهوا بالفسق واتباع الزواني أسر & | 20 سنين & شمشون بن مانوح من سبط داني \\
\hline في سلامة وإيمان بلا رئيس يجمعهم . & | 40 سنة & دبر نو اسرائيل بعضهم بعضا \\
\hline على الإيمان. & | 20 سنة & الكاهن الهاروني \\
\hline 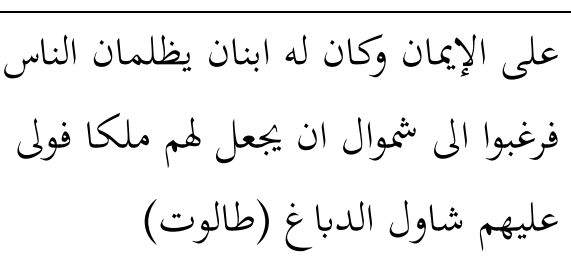 & قيل 20 وقيل 40 & شموال بن فتان النبي من سبط افرايم \\
\hline و والفو أول ملك كان لهم ويصفونه بالنبوة & | 20 سنة & شاول من سبط بنيامين (طالوت) \\
\hline 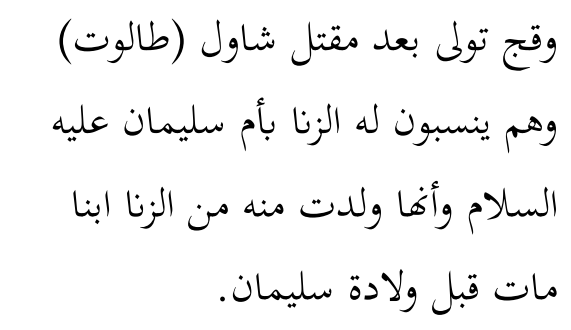 & | 40 سنة & داود عله السلام \\
\hline 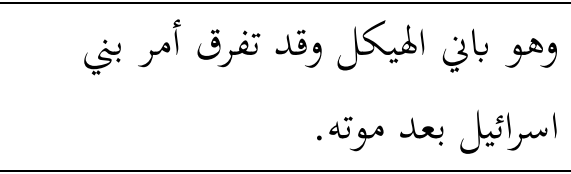 & | 40 سنة & سليمان عليه السلام \\
\hline
\end{tabular}

وقد علق ابن حزم على هذا التاريخ بقوله "فاعلموا الآن أنه من وقت دخلوا الأرض المقدية إثر موت موسى عليه السلام الى ولاية أول ملك لهم وهو شاول المذكور، سبع ردات فارقوا فيها الإيمان واعلنوا عبادة الأصنام (بين ثمانية اعوام واربعين نة في ك ردة) فتأملوا اي كتاب يبقى مع تمادي الكفر ورفض الإمان هذه المدد الطوال، ليس على دينهم واتباع كتابهم أحد على ظهر الأرض غيرهم".

وابن حزم هنا ينكر سلامة التوراة مع تلك الفترات الطوال من الكفر التي يقر فيها كاتب التوراة أن الجميع يكفر ولا يبقى واحد على الإيمان، بل يجاهرون بعبادة الأصنام.

$$
\text { 45 }
$$


أما الفترة التي تفصل مقتل شاول عن انقسام المملكة فليست بالكبية وهي تضم فترة حكم داود ثم ابنه سليمان عليهما السلام، وبعد وفاة هذا الأخير انقسمت المملكة المى قسمين، مملكة يهوذا وتضم سبطي يهوذا وبنيامين ومملكة

$$
\text { اسرائيل وتضم باقي الأسباط العشرة. }
$$

\section{2- حال التوراة في مملكة "يهوذا" من بدايتها الم فمايتها:}

وهي التي تضم في يهوذا وبني بنيامين لبني سليمان، وقد عرفت عشرين ملكاً، كان معظمهم على الكفر وعبادة

$$
\text { الأوثان، خلاصة تاريخهم في الجدول التالي: }
$$

\begin{tabular}{|c|c|c|}
\hline طبيعة الحكم ومعلومات إضافية & مدة الحكم & 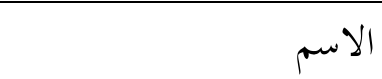 \\
\hline كان على كفر & ( ) 17 سنة & رحبعان بن سليمان \\
\hline كان على كفر & 6 أعوام & أبيا بن رحبعام \\
\hline كان على الإيمان & | & أنشا بن ابيا \\
\hline كان على الإيمان & 25 سنة & يهوشفاط بن اشا \\
\hline لا يوجد بيان لطبيعة حكمه & 8 أعوام & يهورام بن يهوشفاط \\
\hline على الكفر وقد مات مقتولا & سنة واحدة & أحزياهو بن يهورايم \\
\hline كتبت عمانت على الفسق ملك العشرة أسباط & 6 أعوام & أمه "عثلياهو" \\
\hline 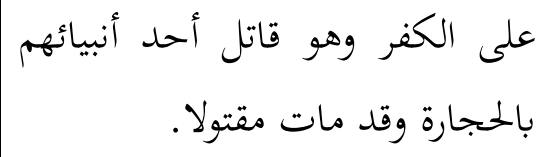 & (40 سنة & حفيدها يؤاش بن أحزياهو \\
\hline المقان على الكفر ثم قتل وفي أيامه ملك المبك & 29 سنة & أمصياهو بن يؤاش \\
\hline
\end{tabular}

$$
\text { 46 }
$$




\begin{tabular}{|c|c|c|}
\hline "عاموص". & 52 & عزياهو بن امصياهو \\
\hline لا يوجد بيان لطبيعة حكمه & 16 سنة & يوشام بن عزياهو \\
\hline على الكفر & | 16 سنة & أحاز ين يوشام \\
\hline 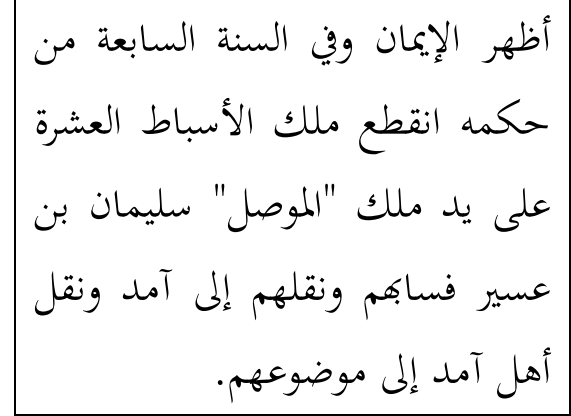 & 29 سنة & حزقيا بن أحاز \\
\hline 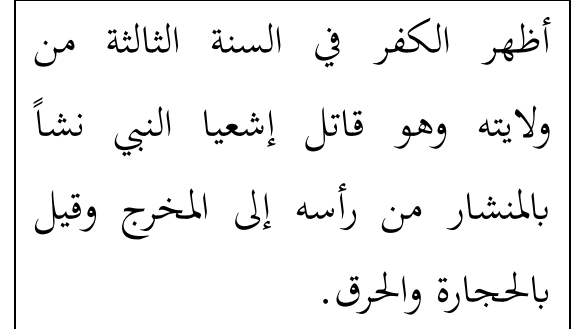 & 55 & منسى بن حزقيا \\
\hline على الكفر. ع & سنتين & آمون بن منسى \\
\hline ولايته الى أن قتله ملك مصر. الإيمان في السنة الثالثة من & - & يوسيا بن آمون \\
\hline 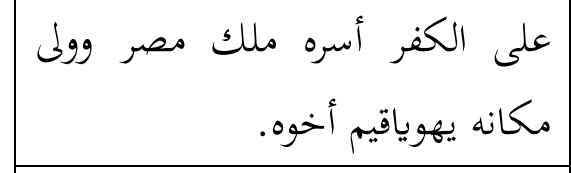 & ثلاثة أشهر & ي يهويحوز بن يوشيا \\
\hline 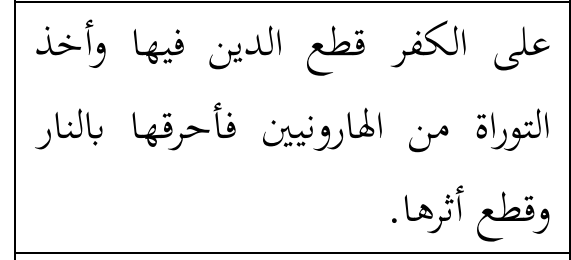 & 11 سنة & يوهويقيام بن يوشيا \\
\hline 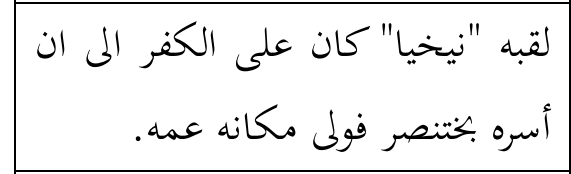 & ثلاثة أشهر & يهوياكين بن يهوياقيم \\
\hline كان على الكفر إلى أن اسره بختنصر & | 11 سنة & متنيا بن يوشيا لقبه "صدقيا" \\
\hline
\end{tabular}


علق ابن حزم على ما سبق بقوله: "فاعلموا الآن أن التوراة لم تكن من أول دولتهم الى انقضائها إلا عند الهاروني الكوهن الأكبر وحده في الهيكل فقط"47 وقد أشار الى أن فتة ملكهم التي دامت حوالي أربعمائة سنة، حكمهم فيها تسعة عشر ملكا وامرأة هي تمام العشرين كانوا كلهم على الكفر حاشى خمة منهم كانوا على الإميمان. وقد وصلت المدة الفاصلة بين قترة الإيمان والكفر الى أكثر من مائة وستين عاما في احدى المرات، كلها في عبادة الأوثان وقتل الأنبياء، واستمر حالهم كذلك الى أن سباهم بختنصر وهدم البيت واستأصل أثره ولم تكن التوراة عند أحد إلا فيه، فكيف تسلم عبر هذه القرون الطويلة وهي في الهيكل الذي كانت الغارات لا تغفل عنه ولا تترك فيه

\section{3- حال التوراة في مملكة "اسرائيل" من بدايتها إلى نهايتها:}

وقد ضمت هذه المملكة الأسباط العشرة، أما ملوكهم "فلم يكن فيهم مؤمن قط، ولا واحد فما فوق، بل كانوا كلهم معلنين عبادة الأوثان، مخيفين للأنبياء مانعين القصد المى بيت المقدس ولم يكن فيهم نبي قط الا مقتولا أو هاربا مخافا"49 ونجمل حال ملوكهم في الجدول الآتي:

\begin{tabular}{|c|c|c|}
\hline طبيعة الحكم ومعلومات إضافية & مدة الحكم & 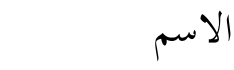 \\
\hline (إفرايمي) كان على الكفر & 24 سنة & برعام بن ناباط \\
\hline تخم قتل هو وبميع اهل بيته كان على & سنتين & ناداب بن يرعام \\
\hline من بني يساخر بن ليئة كان على & 24 سنة & بعشاين إيلا \\
\hline
\end{tabular}

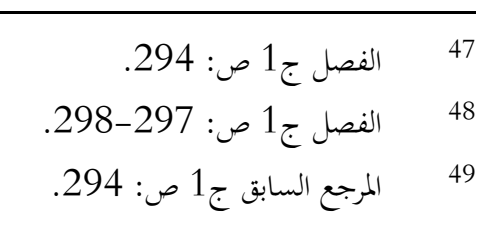




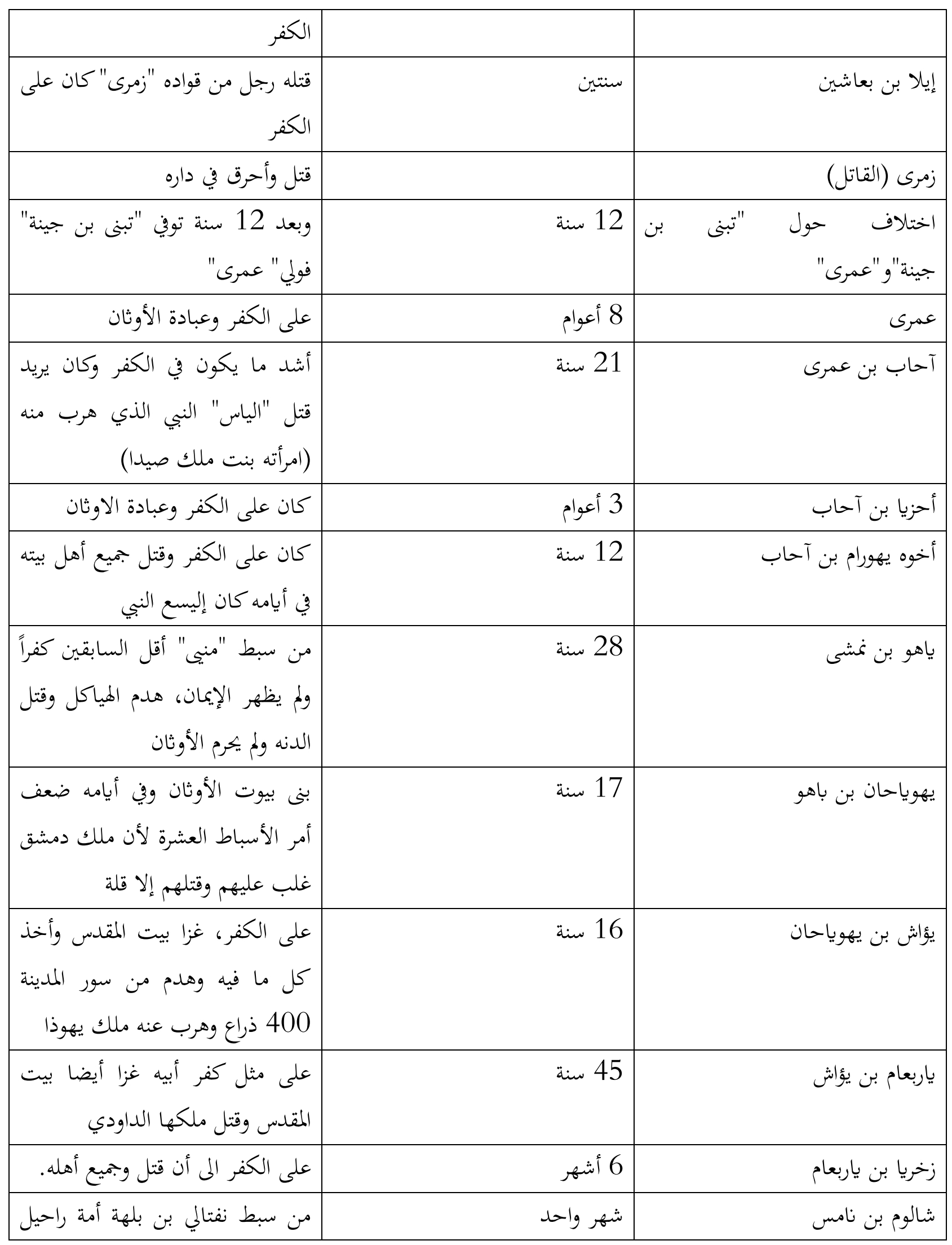




\begin{tabular}{|c|c|c|}
\hline وكان على الكفر ثم قتل & & \\
\hline من سبط يساخر بن ليئة كان على & 20 سنة & مياخيم بن قارا \\
\hline ولى الكفر وعبادة الأوثان قتل هو & سنتين & محيا بن مياخيم \\
\hline 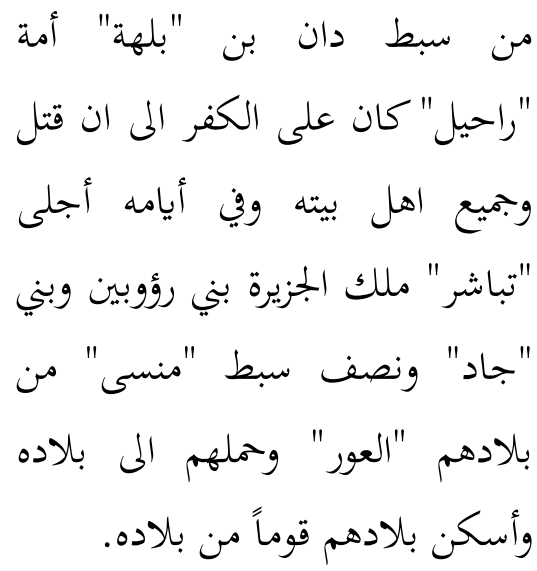 & 28 سنة & ناجح بن مليا \\
\hline 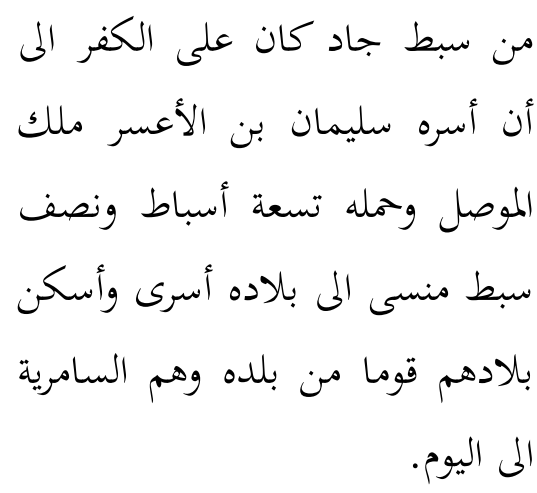 & 7 سنين & هوشع بن أيلا وهو آخر ملوك \\
\hline
\end{tabular}

يتبين من خلال هذه الجداول التي تلخص لنا حال أوليائهم وملوكهم منذ موت موسى عليه السلام الى سبي البابلي، أن اغلبهم كانوا على الكفر، بجاهرين بعبادة الأوثان، متبعين للشهوات والملذات، وذلك بشهادة الكتاب المقدس نفسه، بل إن التوراة خلال هذه القرون الطويلة لم تكن متداولة بل كانت دائما بيد الكوهن الأكبر، المى أن أقيم الهيكل فوضعت فيه ولم تكن عند أحد، أضف الى ذلك أن كل الغارات التي كانت تصيبهم كانت تفرغ الهيكل من كل ما فيه، هذا وفد تعرضت التوراة للتمزيق والإحراق غير ما مرة، فكيف يدعي مدع بنجاتها من كل هذا 
"إنها من إملاء عزرا الوراق الماروني وهم مقرون أنه وجدها عندهم وفيها خلل كبير فأصلحه!!.. وكانت كتابته

لها بعد سبعين سنة من خراب البيت، وكتبهم تدل على أنه لم يكتبها ولم يصلحها إلا بعد نحو أربعين سنة من رجوعهم الى البيت بعد سبعين عاما السالفة الذكر، ولم يكن فيهم حينئ ببي أصلا، ومن ذلك الوقت انتشرت التوراة ونسخت وظهرت ظهورا ضعيفا ولم تزل تتداول الى أن جعل "انطاكيوس" الملك وثنا للعبادة في بيت المقدس، وأخذ بني اسرائيل بعبادته ثم تولى أمرهم في كل قرية وذلك بعد هلاك دولتهم بأزيد من أربعمائة سنة.. ثم إن في التوراة التي ترجمها السبعون شيخا لبطليموس الملك بعد ظهور التوراة خخالفة للتي كتبها عزرا"50 فلا سبيل إذاً للقول بنجاة التوراة!

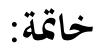

لقد تناول ابن حزم لنصوص العهد القديم بالدراسة والنقد نقطة من أهم نقط مشوعه النقدي للديانات المخالفة للإسلام،هذا المشروع الذي عنونه ب "الفصل في الملل والأهواء النحل" وصاغه صياغة منهجية دقيقة استعصى فهمها غلى الكثيرين ممن تناولوا مشروعه بالدراسة، وما تلك النماذج الي قدمنا في قراءتنا هذه إلا غيضٌ من فيض ما أتى به من أدلة دامغة لا تدع بجالا للشك في النتيجة المتوصل اليها والقائلة بتحريف نصوص العهد القديم المتداول بين الناس وعدم نسبتها المى من نسبت اليهم، بل بالتأكيد على أها بجرد كاتب تاريخي دوّن فيه "عزرا الوراق" تاريخ بني اسرائيل حسب ما توفر لديه من معلومات.

وللوصول الى هذه النتيجة استعمل ابن حزم منهجين اثنين، فاعتمد المنهج الفيلولوجي أثناء تعرضه لنقد مضامين نصوص العهد القديم وعرض بعضها على بعض، والمنهج التاريخي لبيان استحالة سلامة التوراة من التحريف في تاريخ بني اسرائيل الذي كانت سمته الأساسية هي الكفر والردة والحروب والفتن، منذ عهد موسى عليه السلام والى عهد بطليموس الذي ترجم له السبعون شيخا التوراة. وقد ركز في المستوى الأول على الأسفار الخمسة المنسوبة الى موسى عليه اللام وكذا الأسفار المنسوبة الى أنبيائهم ليؤكد بطان هذا الادعاء، وركز في المستوى الثاني على ما جاء في الأسفار الأخرى وخاصة أسفار القضاة الأول والثاني والملوك الأول والثاني من أحداث تاريخية، ليصل في النهاية الى سلى أن هذه الأخيرة هي خير دليل على ضياع التوراة الأصلية وتعرضها للتحريف والتبديل، كما تعرضت للحرق والتمزيق.

$$
\text { 50 }
$$


أفلا يدفعنا كل هذا للتساؤل عن أولى الأمم بالارتباط بنصها المقدس وجعله أصلا لمعتقداتما وإطا لسلوكياتا؟ أيعقل أن يتشبث غيرنا بما عندهم من نصوص مع عظيم علتها، فيحكموها في كل صغيرة وكبيرة؟ ونجعل نحن كتاب الهدى الذي لا يأتيه الباطل من بين يديه ولا من خلفه وراء ظهورنا! 